\title{
An Analysis on the Construction Technology and Management of Water Resources and Hydropower Projects
}

\author{
Yong Xiao $^{1}$, Jidong Chai ${ }^{1}$, Shun Xiao ${ }^{2}$ \\ 1. China Water Resources and Hydropower First Engineering Bureau Co., Ltd., China \\ 2. China Railway Fifth Bureau Group Sixth Engineering Co., Ltd., China
}

\begin{abstract}
As an important national infrastructure, the construction quality of water conservancy and hydropower projects is not only related to people's production and life, but also directly linked to the development of the national economy. Therefore, ensuring the quality of construction works is of great significance. The construction quality of water conservancy and hydropower projects depends to a large extent on the level of construction technology. In addition, construction technology is also inextricably linked to construction efficiency and construction cost. Therefore, construction companies must pay attention to the construction technology management of water conservancy and hydropower projects, and adopt scientific and reasonable construction technology to ensure the project according to the actual situation of construction quality, give full play to the economic and social benefits brought by the construction of water conservancy and hydropower projects.
\end{abstract}

Keywords: water resources and hydropower engineering; construction technology; management

\section{Introduction}

The construction scale of water conservancy and hydropower projects is large, the cycle is long, and the construction technology is high. The construction quality is easily affected by various factors. The construction management of water resources and hydropower projects has the following characteristics: It involves more content. Water conservancy and hydropower construction management has direct links with many departments, including transportation departments, environmental protection departments, and urban construction departments, and other factors will restrict its management work; the construction environment of water conservancy and hydropower projects is harsh. Compared with other projects, the construction environment of water conservancy and hydropower has certain particularities, and it is generally carried out in difficult places such as valleys and rivers. The construction is very difficult; water conservancy and hydropower projects cover multiple disciplines, and the construction management is highly systematic and comprehensive, not only includes knowledge in hydropower, but also includes knowledge in geology, law, meteorology and management, which requires higher requirements for construction managers.

Water conservancy and hydropower construction technology adopts scientific and reasonable technical means to realize the conversion of water energy into electric energy. The management content of water conservancy and

Copyright $(2019$ by author(s) and Frontier Scientific Research Publishing Inc.

This work is licensed under the Creative Commons Attribution International License (CC BY 4.0).

http://creativecommons.org/licenses/by/4.0/ 
hydropower construction technology is: in the actual construction process, control the construction technology methods and ideas, so as to improve the efficiency of the conversion of water energy into electrical energy, and effectively protect the economic benefits of water conservancy project construction. Water conservancy and hydropower construction technology is closely related to management work. When constructing water conservancy and hydropower projects, the construction unit must take scientific and reasonable measures to integrate technology and management to ensure the smooth construction of water conservancy and hydropower projects.

\section{Overview of Related Theories}

2.1 Overview of construction technology and management of water resources and hydropower projects

In the construction of water conservancy and hydropower projects, how to control the quality and progress of water conservancy projects is the key to water conservancy projects. However, the construction technology of water conservancy and hydropower projects is directly related to the construction quality and progress of the entire project. Therefore, in the construction of water conservancy projects, how to use advanced construction technology of water conservancy and hydropower projects plays an important role in improving construction efficiency, strengthening construction quality, and reducing construction costs.

During the construction process, the water conservancy and hydropower project should have a comprehensive understanding and research of the project. Judging from the structural characteristics of the project and the technical standards of the project, it is necessary to conduct in-depth analysis and research to find the best and most reasonable. It is best suited to the actual construction plan of the project, thus laying a good foundation for the quality of the project. In addition, the construction personnel of water conservancy and hydropower projects must have a high level of business and have a strategic idea for the entire project. At the same time, technical communication should be conducted for each construction staff to prepare for the management after the project is completed. Technicians must strictly control the quality. Whether it is large area or small details, they should provide in-depth guidance and supervision to further improve the quality of water conservancy and hydropower projects.

In order to better improve the quality of water conservancy and hydropower projects, it is necessary to establish a complete technical management organization and sign a target contract with the person in charge. The content of technical management is divided into detailed departments, namely mountain engineering design, construction technology, staffing and other aspects. In terms of engineering design, there are mainly engineering survey, planning, construction time, quality to be achieved, required costs, documents after completion, and engineering inspection and maintenance. In engineering design, there are three main aspects, namely inspection of engineering drawings, modification of design and orderly management of design. In terms of construction technology, there are construction technical conditions and applications, summary, preservation of related technical data, etc. The construction personnel include the training of construction technicians and related rules and regulations, as well as related responsibilities, so as to manage all aspects of technology.

2.2 Overview of construction technology and management role and status of water resources and hydropower projects

Water conservancy and hydropower engineering is a basic project for the development of the national economy. It has an important role in promoting the development of the national economy. Scientific and reasonable water conservancy and hydropower engineering construction technology is used to conduct scientific and effective water conservancy and hydropower project construction management, so that water conservancy and hydropower can be effectively guaranteed. The smooth progress of the project construction has enabled the construction of water conservancy and hydropower projects to better serve the people's production and living, and to give better play to the social utility of water conservancy and hydropower projects. 
2.2.1 The role and status of construction technology for water conservancy and hydropower projects

Water conservancy and hydropower engineering is a technology that uses water conservancy and hydropower engineering to generate electricity. Hydropower is a clean energy and a renewable energy source. The further development of water conservancy and hydropower engineering shows that China has made great achievements in the construction technology of water conservancy and hydropower engineering improvement. In the process of construction of water conservancy and hydropower projects, we must focus on construction technology, because construction technology of water conservancy and hydropower projects is the top priority of water conservancy and hydropower projects. It is the foundation and the same guarantee. Only the construction technology of water conservancy and hydropower projects can be better. To ensure the smooth progress of the construction of water conservancy and hydropower projects, it is conducive to the water conservancy and hydropower projects to be able to exert their actual utility better after the construction is completed, and to play a huge effect for the people's production and life.

2.2.2 The role and status of construction management of water resources and hydropower projects

The construction management of water conservancy and hydropower projects can provide certain support for the construction of water conservancy and hydropower projects, and is the basis for ensuring the smooth progress of water conservancy and hydropower projects. Only scientific and effective water conservancy and hydropower project management can serve the construction of water conservancy and hydropower projects. Good engineering management can make the construction site of water conservancy and hydropower projects orderly, ensure the smooth progress of construction work of water conservancy and hydropower project construction staff, scientifically and rationally control the manpower of all parties, and analyze specific problems and optimize the allocation of resources. The specific utility of the application is brought into full play.

\section{Construction Technology of Water Resources and Hydropower Projects}

\subsection{Diversion technology}

Because of the nature of the water conservancy project, the project should be constructed in some locations with sufficient water resources. People construct water conservancy projects in some large river locations. The climate will affect the river. If the precipitation is excessive, it will cause the river water to rise. In order to ensure stable operation after the completion of the project, diversion technology construction is required. The construction of the cofferdam is reflected in this link. The use of diversion technology can prevent floods caused by rainfall or other factors to a certain extent, providing a flood prevention effect. This also provides protection for the project to a certain extent and promotes the improvement of construction progress. In this regard, in the specific construction process of this project, it is necessary to analyze the construction situation at the construction site in accordance with professional guidance, further understand the actual situation of the river, and conduct diversion construction for the cofferdam according to its own construction conditions. In this way, the function of water flow engineering can be guaranteed. However, in the specific construction process, because the cofferdam construction occupies the original river channel, it promotes the narrowing of the river channel. When the water flow in the river increases, it is difficult to discharge smoothly, which makes the diversion work more difficult, and also increases the pressure, this requires full attention to the effective management of cofferdam areas.

\subsection{Dam filling}

During the concrete construction process of the water conservancy project, the dam is an important carrier of the project and can provide guarantee for the construction of the project. Filling the dam is to fill the dam with soil and divide the dam. In the specific construction process, in combination with the specific conditions in different regions and the differences between different construction conditions, the selection of equipment and the modern development are 
reflected in the application of advanced construction machinery, and during the specific application of different machinery, the equipment must be regularly carry out maintenance to make it always in the best operating condition and improve construction efficiency.

\subsection{Earth dam seepage prevention and reinforcement}

During the use of earth dams, it may be caused by water erosion due to different factors. The scale of water conservancy projects is relatively large and the gravity is large. Therefore, it is necessary to attach great importance to scientific prevention and treatment of earth dam infiltration. After the earth dam is eroded and infiltrated, the dam body can be fixed using grouting technology to form an integrated structure to further strengthen its bearing capacity. The construction staff performs splitting and curtain grouting operations on the dam foundation and abutment. They also need to conduct anti-seepage construction, establish a seepage system that can connect different dams, further strengthen the seepage prevention function, and finally promote the height of the water body in the low dam being lowered, this fundamentally prevents the country from seeping and eroding the water body. In the concrete grouting construction process, it is necessary to set the grouting scientifically based on the actual situation, and then set different forms of signs in combination with different grouting holes. Normally, when setting the main hole, you need to understand the dam line first, and then adjust it appropriately. The auxiliary hole is 1.5 meter above the axis, maintaining the normal distance of the hole, and at the same time ensuring its vertical construction to improve the anti-seepage effect.

\section{Water Resources and Hydropower Engineering Construction Management}

\subsection{Establishing technology management system}

When signing a water conservancy construction contract, it is necessary to further analyze the relevant details in the contract, and further check the strength of the project. In the implementation of the specific construction process of the water conservancy and hydropower project, the response plan and the specific conditions of the construction process need to be analyzed, and then formulate a scientific and feasible technical charter to further achieve project supervision, and at the same time, a qualified quality inspection team must be established to manage it in sections to ensure the quality of project construction.

\subsection{Technician management}

Corresponding technicians need to further clarify their own work tasks in accordance with the project management situation, and divide their responsibilities to avoid quality problems in different details, so as to avoid damage to the project and provide guarantee for project quality. In order to promote the enthusiasm and initiative of relevant technical personnel, a reward mechanism can be set up in the corresponding project management, and through this reward mechanism, the technical staff's sense of responsibility can be improved. Regular technical training is also required for technicians. In this way, the thinking and communication and cooperation capabilities of technicians must be effectively improved. Improve the communication and cooperation skills of technicians, and allow technicians to learn from each other during specific construction, thereby improving the quality of engineering construction.

\subsection{Construction design management}

The management of construction design includes construction plans, construction organization forms, and management skills. The management of these contents is mainly to develop comprehensive documents for the management of the corresponding construction projects. The contents include an introduction to the preparation of documents, as well as organizational design, overall layout, design schemes, construction progress and resources, and quality monitoring. Management of design content uses advanced management methods as much as possible, and make scientific and reasonable management of design content. At the same time, it is necessary to improve the water conservancy and 
hydropower project construction schemes and equipment functions in a timely manner, and actual operation methods For further improvement, especially for some relatively complex segmented construction plans, in the specific management process of this content, it is necessary to make scientific connections between technical improvements and organizational implementation methods.

\subsection{Drawing review}

Before the specific construction of water resources and hydropower, the construction drawings need to be closely inspected, and the corresponding responsible engineers and professional organizing committees need to conduct a relatively thorough and detailed inspection. Finally, it is comprehensively inspected by the chief engineer of the project department. Only in this way can the engineering construction be carried out. In addition, engineering changes may occur during the specific construction process, which requires corresponding management personnel to communicate the change information in a timely manner to appropriately reduce costs.

\section{Conclusion}

In summary, social and economic development has driven the development of water conservancy and hydropower projects. As a national infrastructure, water conservancy and hydropower projects are important industries related to national economy and people's livelihood, and their construction quality and construction safety must be ensured. In the process of water conservancy and hydropower construction, the level of construction technology greatly affects the construction quality, construction safety, and construction progress. Therefore, construction companies must pay attention to the application and development of construction technology, and continue to explore and study advanced construction technology. And apply it reasonably to the actual construction process, so as to improve the quality of water conservancy and hydropower construction.

\section{References}

[1] Fang Guodong. (2015) Analysis of Quality Monitoring and Management in the Process of Water Conservancy and Hydropower Construction. Henan Water Resources and South-to-North Water Diversion, (08): 1-2.

[2] Wan Shan. (2015) Analysis of Construction Technology and Management of Water Conservancy and Hydropower Engineering Buildings. Jiangxi Building Materials, (13): 120.

[3]Wang Bin. (2016) Analysis of Concrete Construction Management in Water Conservancy and Hydropower Projects. Engineering Technology Research, (08): 167 + 171 . 